\title{
The Semantic Annotation Based on Mongolian Place Recognition
}

\author{
Yila Su, Huimin $\mathrm{Li}^{*}$, Fei Wang \\ College of Information Engineering, Inner Mongolia University of Technology, Hohhot 010051, China. \\ * Corresponding author. Tel.: +86 15661065587; email: xiaomin11116@126.com. \\ Manuscript submitted September 22, 2014; accepted April 3, 2015. \\ doi: $10.17706 /$ jsw.10.5.616-627
}

\begin{abstract}
The Mongolian semantic description is the chief problem in construction of Mongolian semantic web. Particularly, more and more Mongolian websites have been created in recent years, and the number of users is sharply increasing, both of them demand for higher quality of Mongolian information retrieval. This paper is based on the study of Mongolian place name recognition and semantic annotation. Under the background of the semantic web, the paper constructs the place name ontology of Mongolian administrative districts, and compiles Mongolian place name lists and jape rules. With GATE, the system realizes place name recognition and annotation in any Mongolian document. Then it adequately digs out the geographical information of Mongolian document, and realizes structured place names, so that it would be a great help to semantic search of geographic information.
\end{abstract}

Key words: Semantic annotation, place ontology, GATE, JAPE Rules.

\section{Introduction}

Since the early 1980s, the Mongolian information processing has carried out some fundamental infrastructure and basic theoretical research, and also developed a few applications, as in [1], [2], such as the establishment of various corpus, the formulation of coding standards, research for Mongolian grammar and semantic attribute, manufacturing Mongolian grammatical information dictionary, and the development of Mongolian electronic language publishing systems and machine translation systems. In reference to Mongolian, the research activities of the semantic of Mongolian verbs, noun, adjective concentrated on information processing has made considerable achievements due to the better foundation of Mongolian grammar study. However, the construction of Mongolian semantic web is still in a relatively inferior position in the field of Mongolian study. Based on the study of Mongolian place name recognition, this article firstly uses ontology technology to build place name ontology of administrative divisions of Inner Mongolia, and then on the basis of the constructed ontology, the paper uses a text common framework GATE, and by compiling the Mongolian place name glossary, running jape grammar rules, to accomplish the recognition and annotation work of place names in Mongolian document, and transform them from the unstructured, semi-structured data into structured data with some knowledge of semantic information, so that they could provide the advantageous conditions for further semantic retrieval or Mongolian Semantic Web building.

\section{The Construction of Place Name Ontology}


Place name ontology is to apply the ontology technique to the field of place name, which is the knowledge generated by the main description of geographic entity and geographic location, that is to say, the place name ontology is the collection of relationship between the commonly recognized terminology in the field of place name and terminology. The construction of place name ontology defines the relationship between term and term semantic under the common understanding of the knowledge of term and the guidance of experts in the field cooperation. In addition, it adds a description for temporal characteristics, which makes the place name change, resulted from changing over time form formal description by formal coding.

\subsection{Place Name Ontology Model}

The core object of place name temporal ontology research is geographical entities. Each corresponding place name represents a geographical entity. Each geographic entity will have three characteristics: time, space and their own property, so we describe a place name from these three aspects. Specific mathematical description ,as in [3], is as following :

$$
P=f(A, S, T)
$$

In which, $\mathrm{P}$ represents place name (Place name); A represents attribute (Attribute), including the relationship of the name, population, attribution, administrative levels, etc under the conditions of given space and time; $\mathrm{S}$ represents spatial characteristics (Space), including spatial extent, coordinates, etc.; $\mathrm{T}$ represents the time (Time), including the names of the time coordinate, spatial extent or location changes in the relationship over time. We subdivides ontology names of a geographical entity sub-model, spatial relationships sub-model, geometry sub-model, event sub-model and time sub-model five-part composition, as in [4], shown in Fig. 1. These five parts formally describe place names with different perspectives, which show rich semantic information of place names.

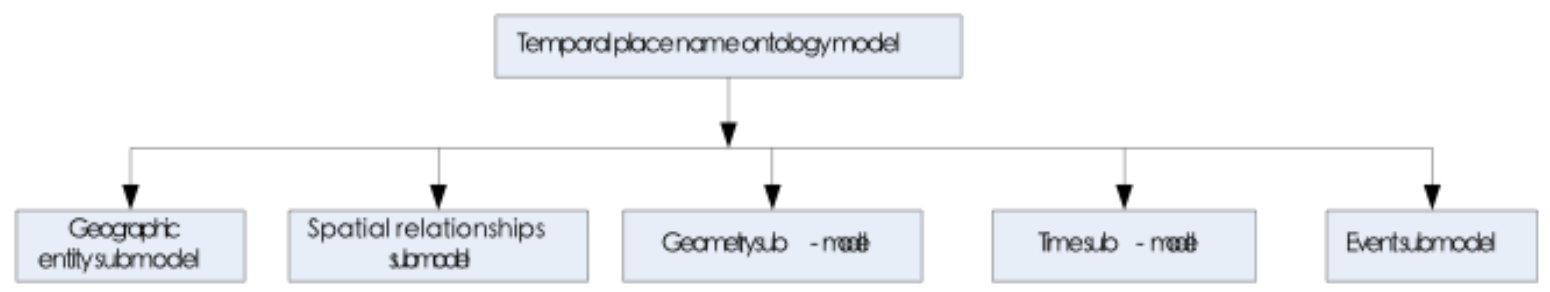

Fig. 1. Five sub-model of place name temporal ontology mode.

\subsubsection{Geographical entity sub-model}

Geographical entity type is an attribute that each geographical entity should have. Each place name corresponds to a geographical entity. In this article, geographical entity types are divided by grade in accordance with administrative divisions. Sub-model is also demonstrated with attribute property of name, population, zip code, administrative subordination, administrative division code, which geographical entity has. Geographic entity sub-model includes administrative divisions and its subclasses existing administrative divisions, history administrative division classes.

\subsubsection{Spatial relationships sub-model}

The setting of topological spatial relationships in this sub-model is simple, because we are not for the GIS data processing and spatial analysis. In this sub-model, place name divided by the country administrative division is regarded as points, and place name divided above the country administrative division is regarded as surfaces, points and surfaces are regarded as the basic topological elements. There is a relationship of contain and within (include and be included) between the two administrative divisions, 
which is inverted, and transitive.

This sub-model does not specifically define spatial relationship classes, but object properties with the definition of OWL object, and then it uses the object properties to represent the spatial relationships among geographical entities. During the process of building ontology, it specified object attribute domains (Domain) and range (Range), through which the two administrative divisions could be associated with each other. To express the space relationship in this way is much closer to the expression of human daily habits and much easier to understand. OWL ontology language expresses the relationship between the object properties as a function of <owl: Functional Property>, inverse function of <owl: Inverse Functional Property>, anti-relationship <owl: inverse Of>, symmetry <owl: Symmetric Property $>$ and delivery sexual $<$ owl: Transitive Property $>$ and so on by providing modeling primitives.

\subsubsection{Geometry sub-model}

Refer to the basic geometric types and the relationship of the simple spatial entity, this sub-model selects and abbreviates appropriately during the process of building the sub-model, and base class graph only take Point and Polygon to represent above the county level and county-level administrative divisions for administrative units, which will make the hierarchy of ontology clearer and make the application more convenient. A geometric object generally regards a spatial reference system as a frame of reference in order to accurately reflect the geometric coordinates of the object resides. In summary, the geometric sub-model defines spatial reference system classes, coordinates classes and spatial extent classes and its subclasses -Point class and Polygon class. Administrative division classes associated with spatial extent through the object class attribute.

\subsubsection{Time sub-model}

Time sub-model defines the class of time that the event occurred as Connected Time class which is an objective entity under current class, the sub-model sets two sub-categories, namely, Instant category represented time points and Interval category represented period of time. Instant class indicates that time point of the event occurred. It uses object properties of occurred At associated with the event class.

\subsubsection{Event sub-model}

Event class is the core class of the sub-models. Geographic entity divides place names class into the place name of history administrative sub-model categories and current existing administrative sub-model categories. Every historical administrative division is caused by a certain event occurred at a certain time. Combined with changes in general administrative divisions, this sub-model sets Split (separation) subclass, Merge (Merge) subclass, Put Under (classified) subclass and Change Name (renamed) subclass under the event class, Change Name subclass can be divided into Change2Historical subclass and Change2Current subclass, corresponding to different situation of place name changing. Every place name of historical administrative division is associated with event class through is Related To, to complete the formal coding that a certain place name of administrative division at some point changed to a place name of historical administrative division due to a certain event.

\subsection{Implement of the Place Name Ontology}

The space ontology of Inner Mongolia administrative units place name uses temporal place name ontology model as modeling framework, it uses Protégé tool to set ontology entities and relationships, as in [5]-[6], according to the names attribute characteristics, time characteristics and spatial characteristics, specific structure as following:

1) Establishing Continuant class and occurrent class in the base class $\langle$ owl: thing $>$, and establishing time class of connected time subclass and event class of event subclass; establishing administrative 
division class of Administrative Districts subclass, coordinates class of Coordinates, spatial extent class of spatial region and subordinate subclass polygon (polygon), point(point), spatial reference system of spatial reference system.

2) Creating subclass in administrative divisions --- Current a districts and Historical a districts, in accordance with the current level of China administrative divisions established administrative divisions class erupted in class today, were established Province Level, Prefecture Level and County Level sub-class and sub-class of four subordinate county subclass - district level (Area), flag (FlagCounty), county-level cities (county level city) and county (county) classes.

3) According to model, establishing event classes(Event) and its subclasse: Split class (split), Merge class (combined), put under class (classified) and change name class (renamed), which change name class under another molecule classes: Change2Current classes and change 2 historical categories, the former indicates that a historical place names change to a place name in use today; the latter indicates one renamed of several times of renaming ,that is to say, a historical names change to another historical names.

4) Settling time class Connected Time class and its subclass Instant and Interval.

5) Defining and describing the space, time and attribute characteristics of administrative division through object property and data type property. Using numerical attribute define the area code (region code), the name referred to (short name), the coordinate values (coordinate value), etc that the administrative divisions have; Using object attribute contain \within express the inclusion relationship between the administrative divisions; Making administrative division be associated with space extent by has spatial region; Making space extent be associated with coordinates by has coordinates; Making historical place name be associated with event class using object attribute is related to; Making event be associated with time by attribute of occurred at and setting passed reflexive and other properties of each attributes.

6) Adding a small amount of instances Individuals, the place name space ontology for administrative units of the Inner Mongolia adds a few targeted place name instances which are at the provincial cities and counties level. Using changes of Hohhot administrative divisions as the prototype of event class, we establish three event class instances which are "suburban two Saihan district", "put under_ and forest", "put under_ Wuchuan". Around the establishment of event class, we add spatial reference system instance, spatial extent instance, coordinate instance, the time instance of the class "T suburban two Saihan" and so on corresponding to event classes.

7) Defining some other semantic relations between exited place name entities for administrative units, such as has capital for has capital (inner mongolia autonomous region, hohhot), which means Hohhot that is the capital of Inner Mongolia Autonomous Region; defining semantic rules through SWRL Rules, such as has capital $(? X, ? Y) \rightarrow$ contain $(? x, ? y)$, which indicates that if the administrative division place name $y$ is the capital of place name $x$, administrative divisions y must be included in the administrative divisions $x$.

The main class diagram of place name spatial ontology for Inner Mongolia administrative division is showed in Fig. 2.

\section{Recognition Based on the Place Name Ontology for Administrative Division}

According to the place name spatial ontology for Inner Mongolia administrative division built in the previous section, combined with corresponding nouns tables and JAPE rules written further enriched, we will accomplish the recognition and semantic annotation in Mongolian document by means of a text common framework GATE. The place named for Inner Mongolia administrative division need to be identified out from Mongolian document and be given some semantic information, which provides building 
conditions for further semantic retrieval or semantic Web.

\subsection{Vocabulary Writing}

Using the GATE to conducted ontology annotation, firstly you need to develop OntoGazeteer dictionary. We need the help of GATE Developer 6.1, using the file system to describe Conceptual relationship library, as in [7], which we used to recognize entity. Conceptual relationship library contains three types of dictionaries: one is that contains instances of ontology concept dictionary, another is that the mapping of concept instance and ontology concept dictionary. The other one is a dictionary of recording features of the dictionary file and labeling features of instance concept. Each row of concept instance dictionary is a instance of the concept, according to the number of concepts. There can be one or more concept instance dictionary, like "City.list" Dictionary recording the place name instance of Inner Mongolia administrative divisions, which intercepts part of the figure of Inner Mongolia municipal administrative place name and Hohhot district-level administrative division place name corresponding to the concept instance in the field, showed in Fig. 3. The second category dictionary lists.def is an index file to access * List file. It specifies the entity type of each *. List, which can be called characteristic dictionary, its format is * List: feature, generally lists.def, which can be seen in Fig. 4. The third type is mapping dictionary, it mapped concept instance dictionary to a certain category in the ontology, its format is *.list: ontology file: Ontology concept. We usually use mapping.def to describe the relationship of list file and domain ontology concept, as shown in Fig. 5. These three file format is the provisions of GATE framework for the domain knowledge, as in [8], these files will be compiled into a finite state automaton when using GATE to tag the named entity. Any automata recognized text fragment through the finite state will attach the Eigen values determined by the type.

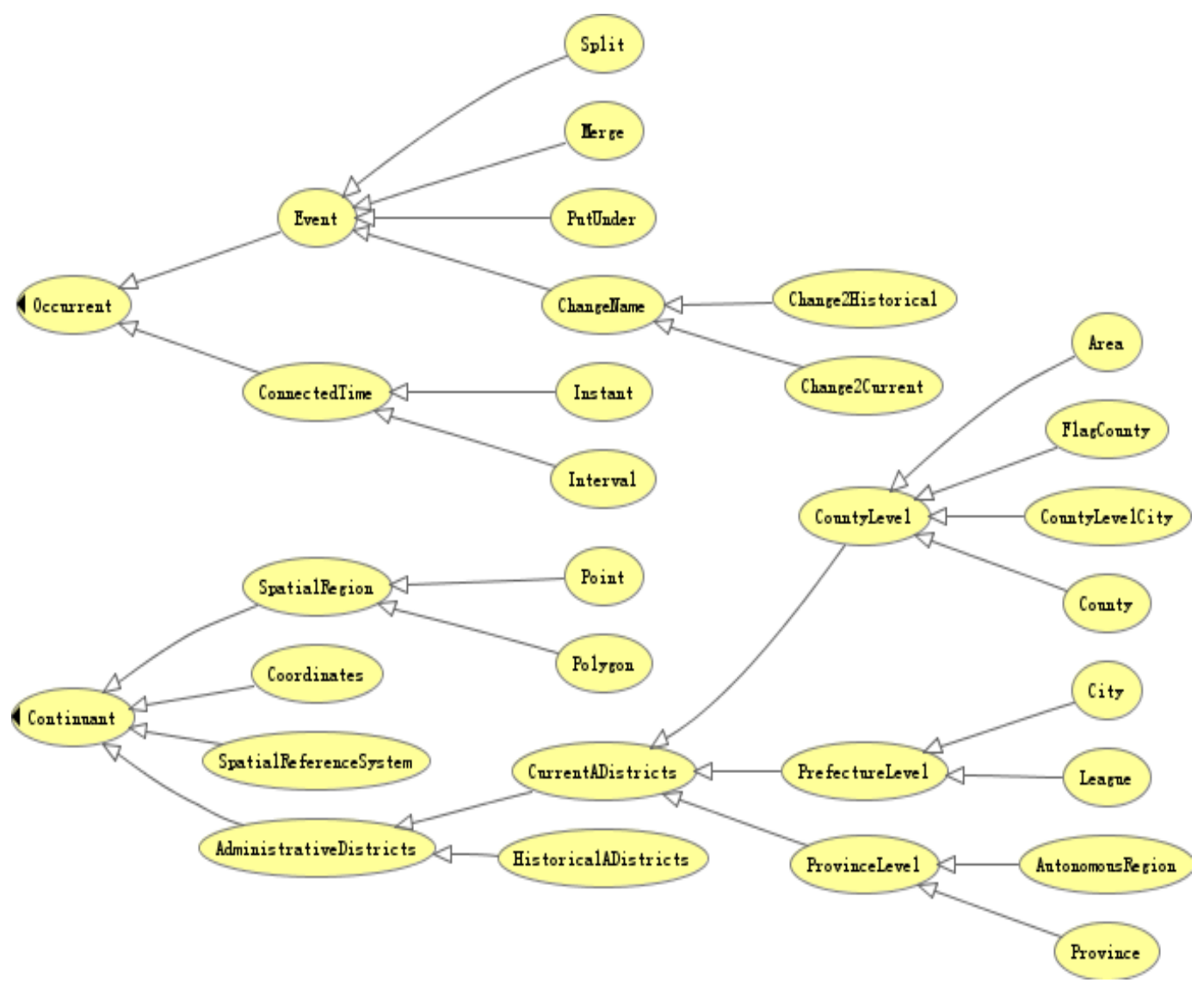

Fig. 2. Graph of inner mongolia administrative divisions place name temporal ontology. 


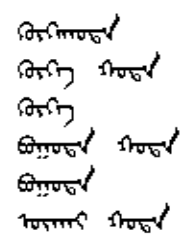

Fig. 3. Concept-instance dictionary city list.

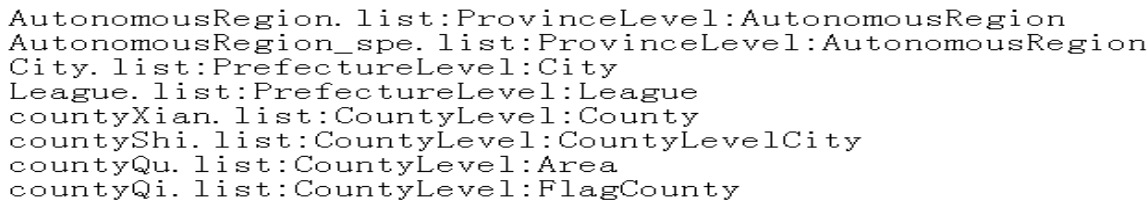

Fig. 4. Indexing dictionary lists def.

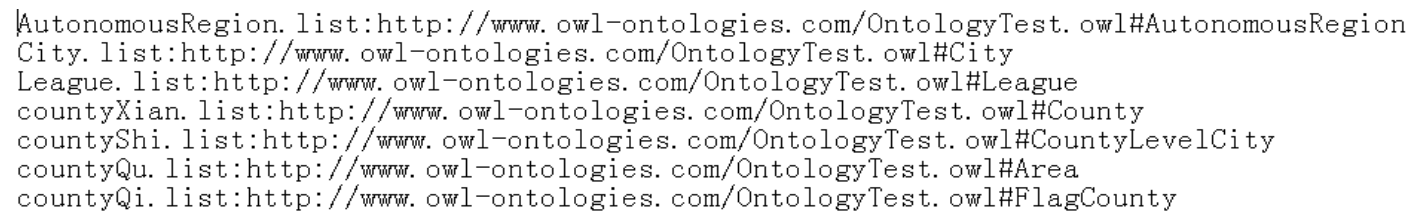

Fig. 5. Mapping dictionary mapping def.

\subsection{Documentation Pretreatment}

Using the Gate's default component ANNIE which deals with English text to preprocess, because we are dealing with Mongolian documents, the identification and labeling is Mongolian place names. Mongolian place name usually is a single word, as in [9], which is similar with English. Unlike the Chinese, you need to use segmentation tools for segmentation. So we can use ANNIE to preprocess the document directly, and to mark the place names in the document, and then we will carry out further semantic annotation.

GATE ANNIE component provides this series of functions, as in [10]. In addition, its vocabulary queries components (Gazetteer) can easily be extended, which can add an instance of the ontology to the dictionary. It would mark the appropriate word or phrase in the document appeared in document. Therefore, this article uses the GATE ANNIE components to pre-process the document, to do punctuate treatment of the document, to tag POS, and to recognize naming entity. When the process is completed, there is not only basic naming entity (such as "names", "organization name", etc.), but also place name instances of the ontology, as is shown in Fig. 6.

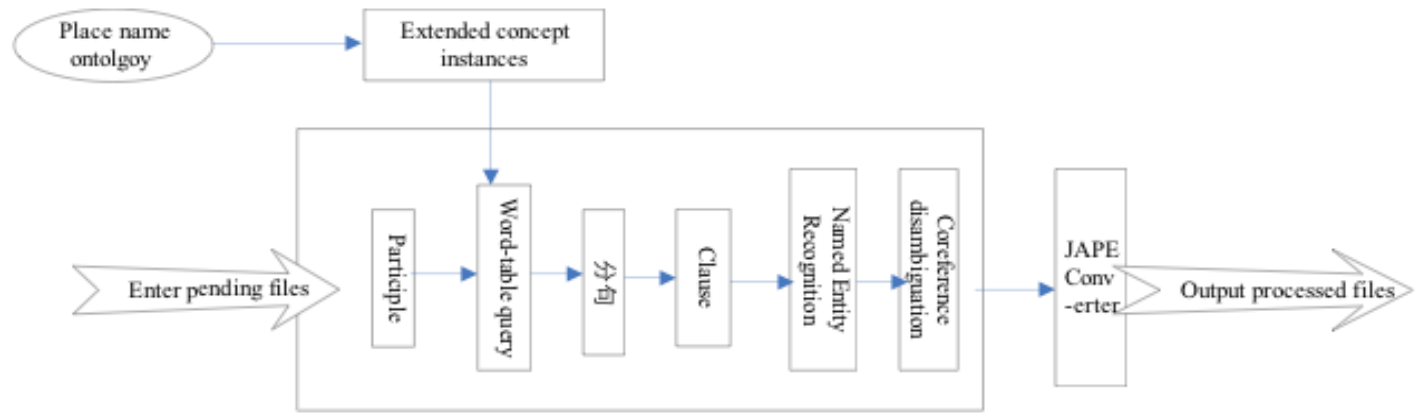

Fig. 6. Flow chart of preprocessing modules.

\subsection{JAPE Rule Authoring}

We can get the results of the original document annotation sets and default label set after a series of preprocessing using ANNIE. We need to focus "Lookup" in default label sets for further processing. Gate 
marks a majorType attribute for each concept instance, the value of the attribute is ontology concept represented by the instance, which is different. So we can further process it using Jape Transducer. JAVA labeling pattern engine provides the annotations of finite state transition based on regular expressions, which is a version of CPSL (Common Pattern Specification Language).We could author the rule which can be identified by GATE through JAPE language, then using these rules to do further processing for the document. For example, the Lookup, mentioned in the paper, identifies several place names, including autonomous regions and municipalities, each with different properties. Based on object feature, JAPE rules are written to distinguish district or city names from all names.

\section{Experimental Validation and Performance Evaluation}

\subsection{Software Implementation}

\subsubsection{Gate}

GATE is abbreviated from General Architecture for Text Engineering. GATE provides users with a graphical development environment that is often applied to a variety of natural language processing projects. It provides remarkable support to all aspects (collecting from the corpus, semantic annotation, reuse, System evaluation) of language processing. The system has been able to support a variety of input processing text formats, including XML, RTF, HTML, SGML, e-mail and general text. As GATE uses Unicode as the default text encoding unified form, it now is able to support nearly 28 languages including Chinese, English, Russian, Japanese and Korean. It also provides the corresponding components in different languages for better support.

GATE divides all the elements of natural language processing software system into different components, known as a resource. We call reusable resources with the common characteristics in GATE as CREOLE(collection of reusable objects for language processing). All text analysis of GATE-based language processing system is done by CREOLE module.

\subsubsection{Annie}

All reusable resources sets in GATE are integrally used in ANNIE (A Nearly-New IE system) which is a English information extraction systems based on rule method. In simple terms, ANNIE is a reusable and extensible set of components, the task is to complete the information extraction and annotation. Specifically, an article which is to be processed could achieve the goal of information extraction by an assembly line of English word query, the English clause, English speech tagging, rule definition of English extraction, the English named entity recognition and English co reference elimination solution.

\subsection{The Experiment}

Next, we choose a press released from China Mongolia News which contains a lot of place name information, as our experimental subjects. For experimental convenience, firstly we copy and paste the article into the word document, and save it as word document format, we take the names identification and semantic annotation experiment mainly on the second and third segment.

1) To load the documents to be processed, as is shown in Fig. 7, named for "example". Language Resources $\longrightarrow$ new $\longrightarrow$ GATE Document. As ANNIE cannot process GATE Document, we can only deal with GATE Corpus. Establishing a GATE Corpus, we add the example to it, pending ANNIE processing.

2) To load ANNIE system. Click the "Load ANNIE System", there are two ways with defaults and without defaults. Although ANNIE is designed to solve the English text processing production, after the experimental trial, it can also support Mongolian document handling to some extent. We select with defaults here.

3) Ontology of loading. Through Processing Resources $->$ new $\rightarrow>0$ OntoGazetteer, we name it as 
ontoexample, note that, the value of listsURL and mappingURL we set is the path of characteristic dictionary lists.def and mapping dictionary mapping.def which is formulated by our conceptual relations database. Click Load button on the "Ontology", and then we choose the created space place name ontology for Inner Mongolia administrative division to complete the loading of ontology, as shown in Fig. 8.

4) Processing with ANNIE, performing document pretreatment process. The ANNIE needs to execute either English file or Mongolian file process according to a certain order of sequence, followed by the document reset -> word -> word table query $->$ punctuate -> tagging -> named entity recognition -> Total refers to eliminate differences. Here, we need to use ontoexample defined by us replace the default ANNIE Gazetteer, and pay attention to the order. To call according to priority until the pretreatment of our experiment documents are completed. Specific process refers to Fig. 9.

As shown in Fig. 10, the term exists in the table to the place names, and GATE could be identified correctly. Since GATE is not entirely good for Mongolian language support, it has difficulties in recognizing the word which is not given by whole word in place name vocabularies. It can only be recognized in a fixed length or syllable. So we cannot write JAPE rules to do further process, we have to recognize them in artificial means. Fortunately, we can also store generic names representing place names as separate records in a gazetteer, in this way, laboratory personnel have a great deal of autonomy to identify whether it is a place name or not artificially, which conduct further semantic annotation for the place name that is not recognized by GATE.

5) JAPE rule authoring and execution. Processing Resources $\rightarrow$ new $\rightarrow$ JAPE Transducer, Named japexample. We choose an authored jape rule storage path in grammerURL. We must select UTF-8 format to encode, so that when jape rule appears Chinese GATE can still show, which merit serious attention. After pretreatment by ANNIE, we got the original GATE annotation set and default label set. Japexampla is imported into processing resource. We run this application on the preprocessed documents. Fig. 11 shows a simple example of jape rule. It can be seen from Fig.12 that we individually identified the place name which meet JAPE rules in documents and displayed as a separate set of Flag.

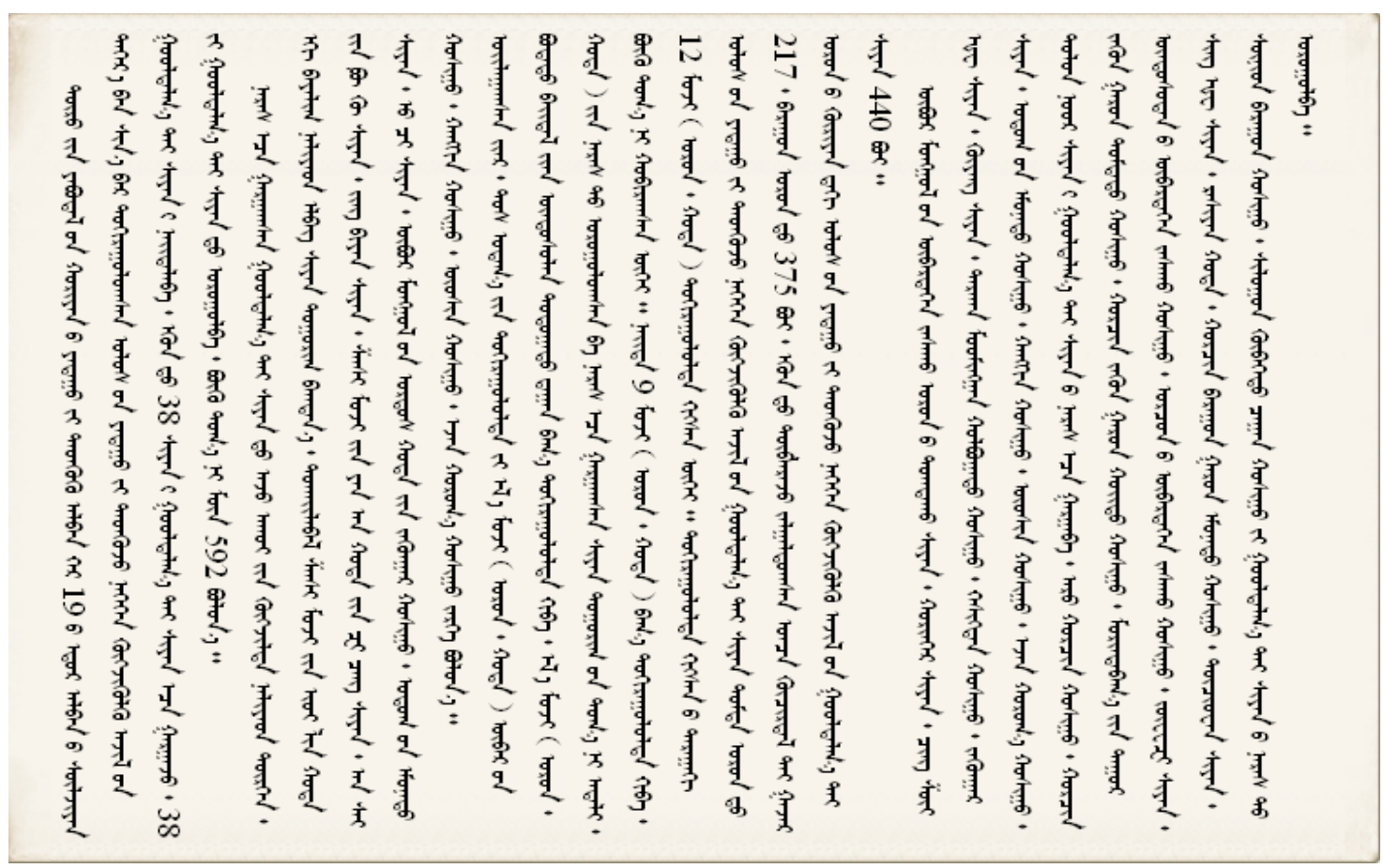

Fig. 7. Processed document. 
File Qptions Iools $\underline{H}$

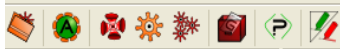

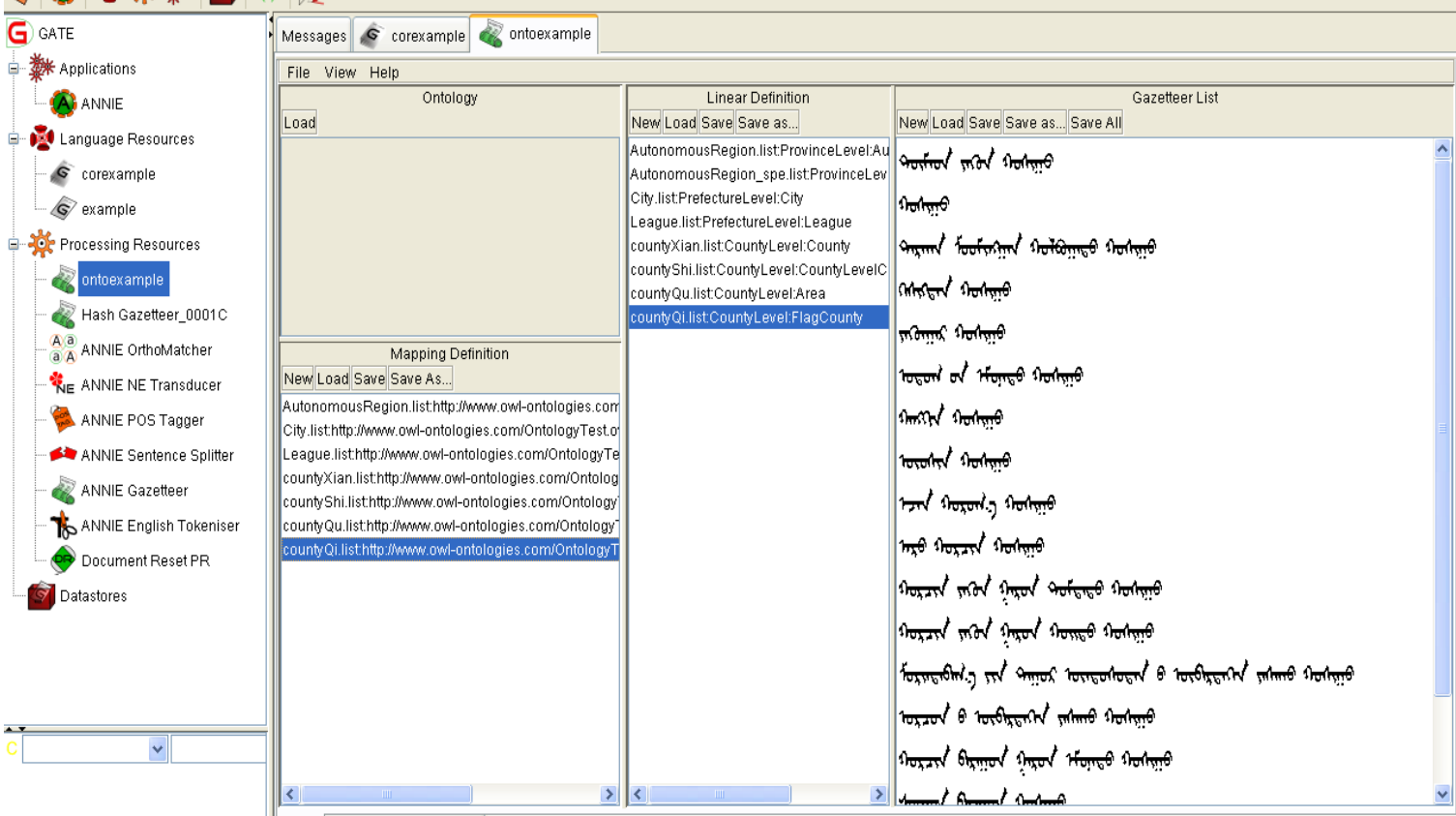

Fig. 8. Ontology of load in.

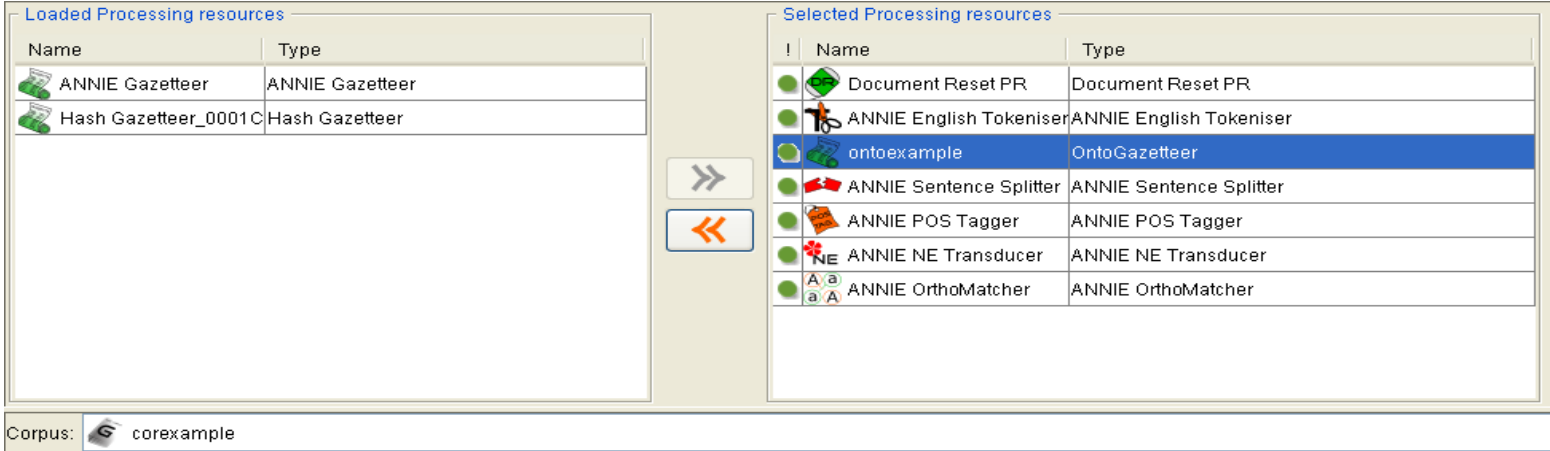

Fig. 9. Preprocessing with annie.

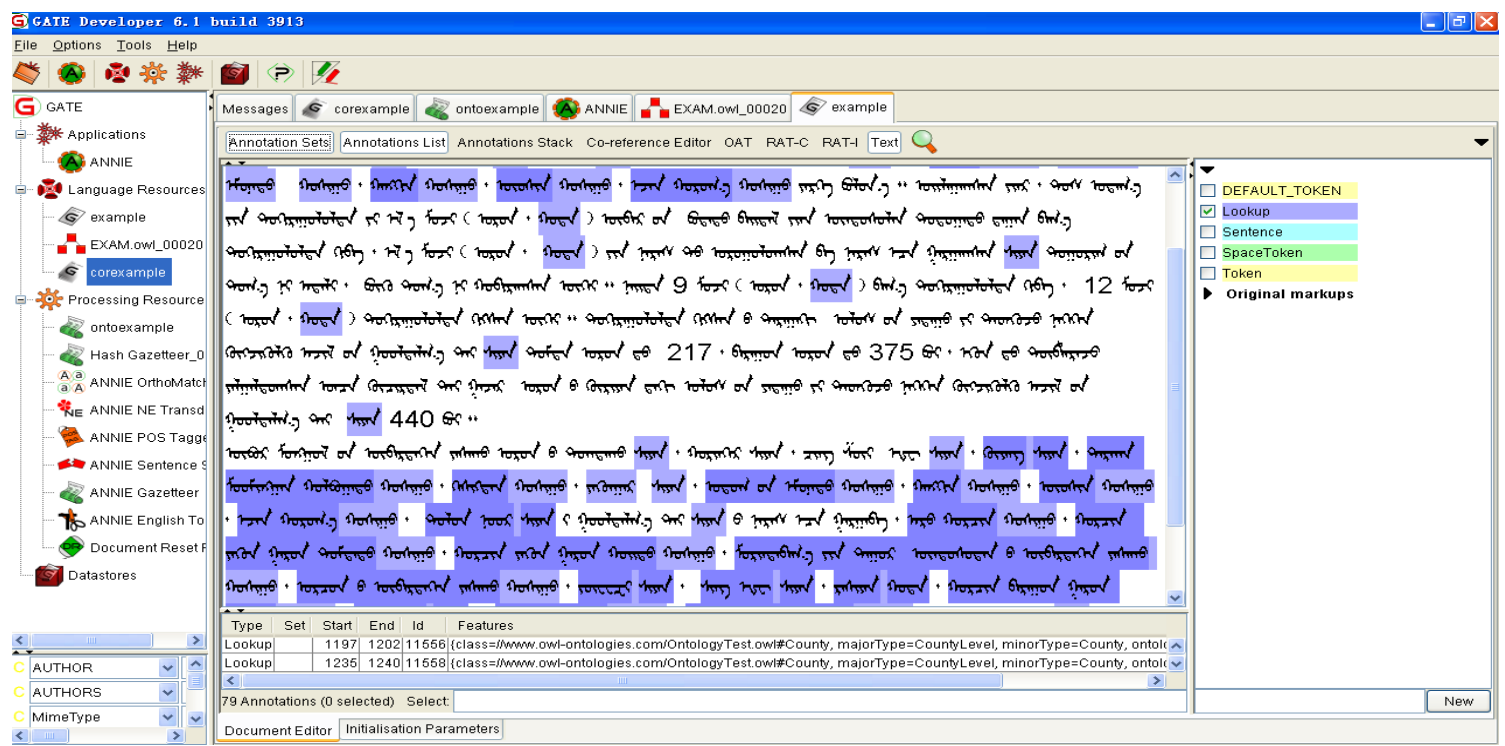

Fig. 10. Result of place name recognition. 


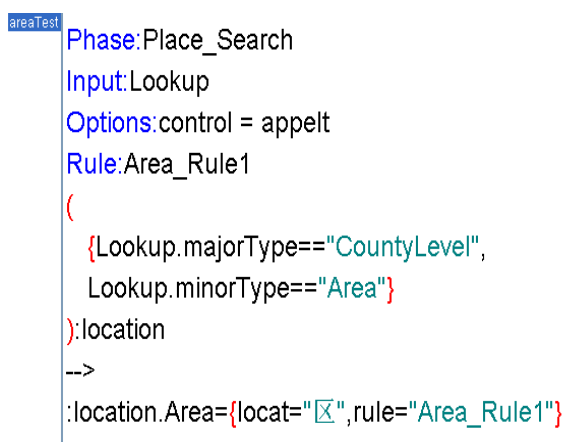

Fig. 11. An example of JAPE.

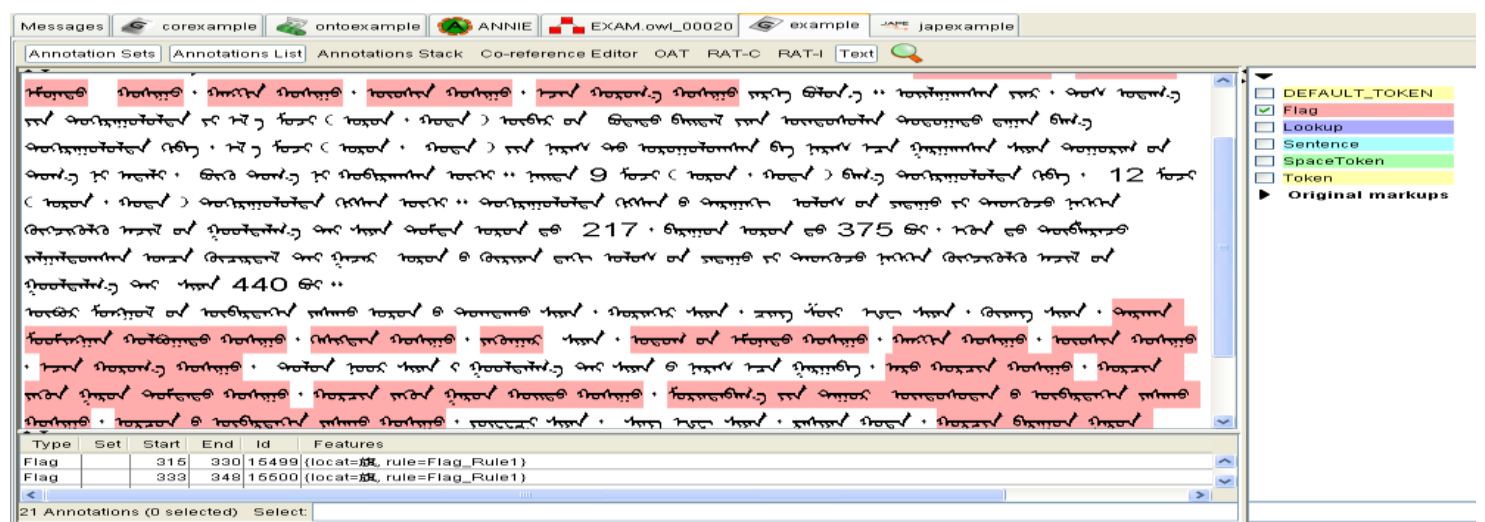

Fig. 12. Result of Test by JAPE rule.

6) Based on Lookup label set, combined with space place name for Inner Mongolia administrative units ontology, we connected place name text fragments with ontology instances and completed information of each place name At last we complete annotation of the document. Finally, we save "example.xml" as Save as XML format and use IE6 to open it. As is shown in Fig. 13 and Fig.14, the place names in the documents are enriched relations of attribute and semantic using ontology. We switch the unstructured data into structured ones which has semantic knowledge.

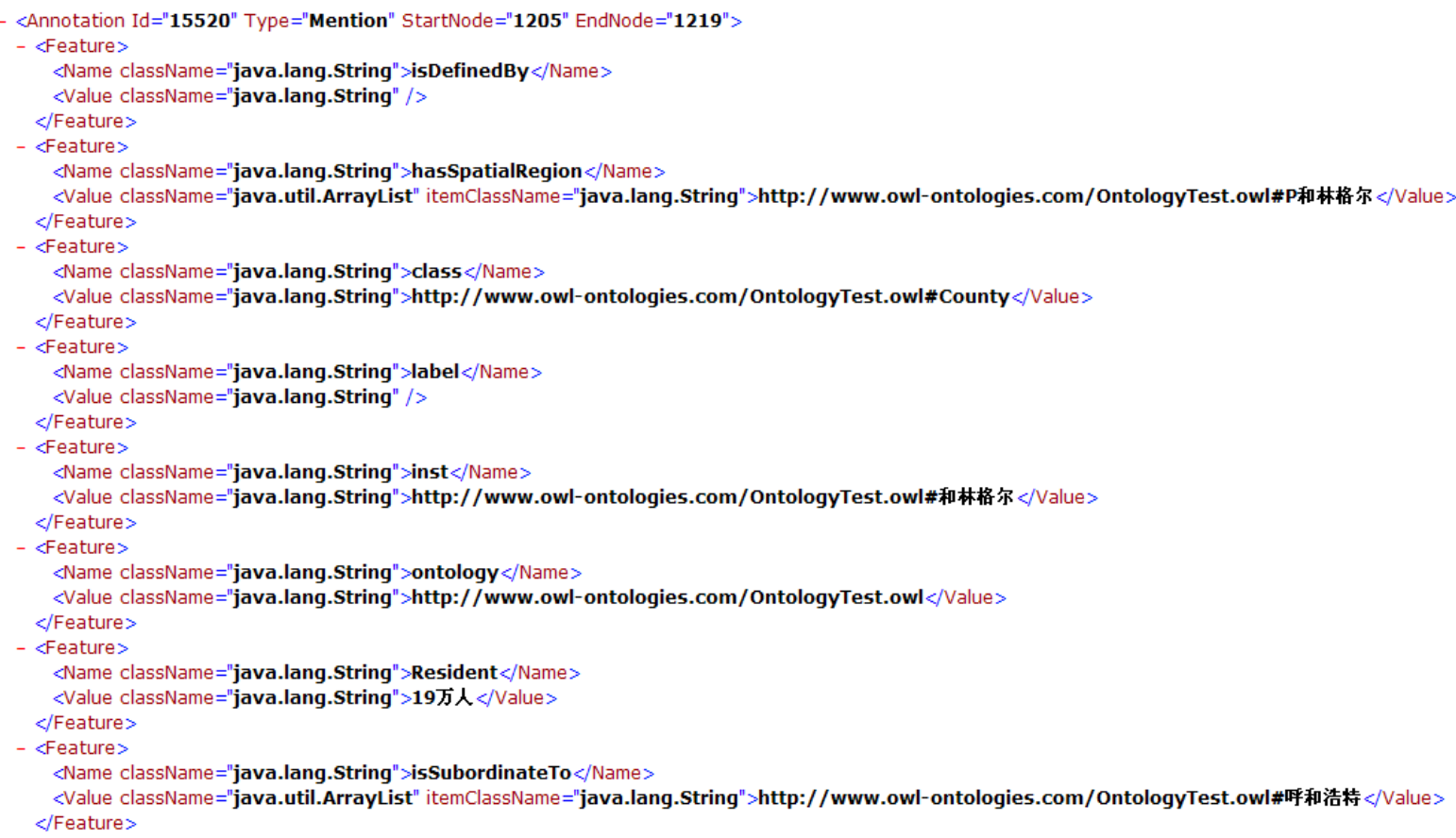

Fig. 13. Tagging. 


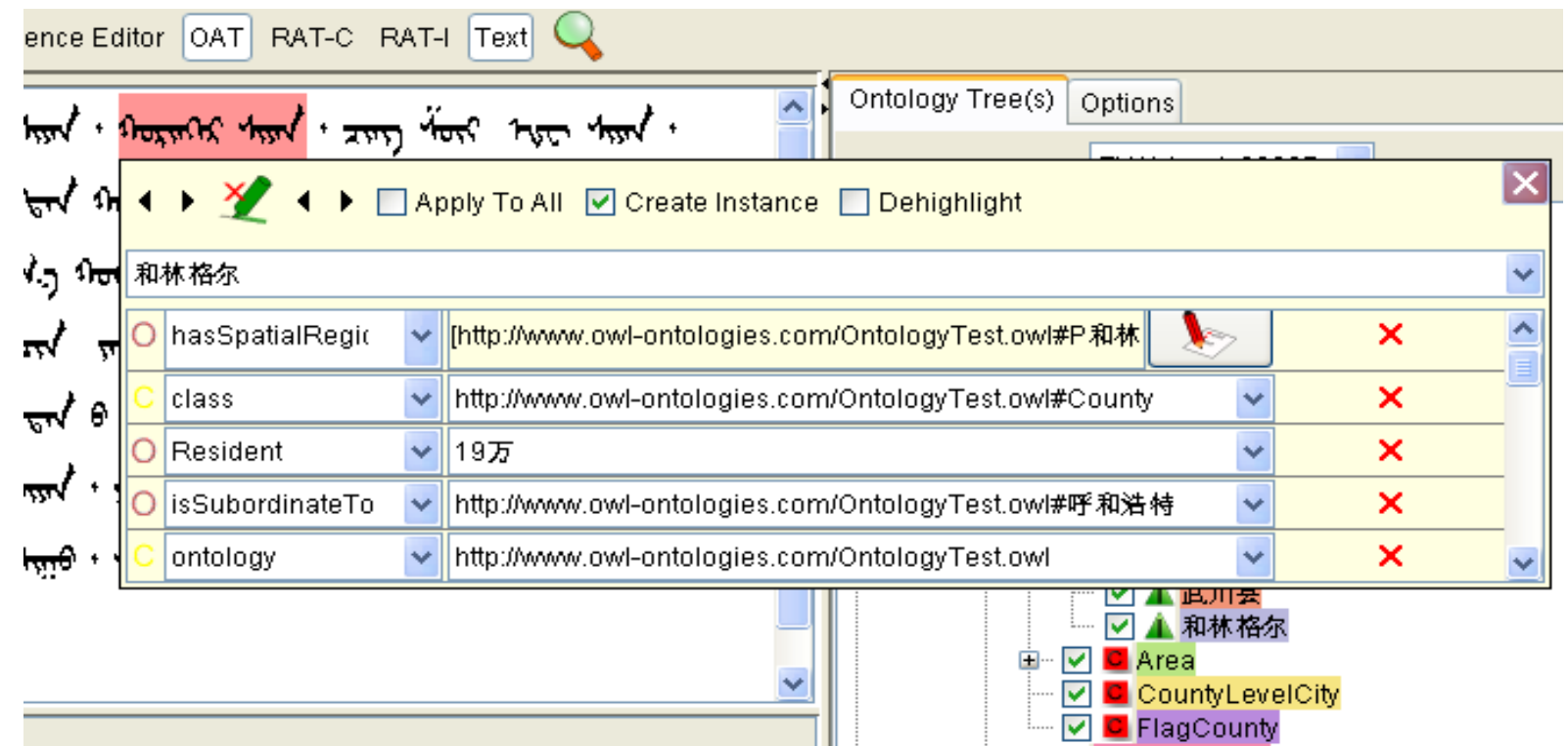

Fig. 14. Result of semantic annotation.

By comparing the correct Chinese translation ofMongolian document selected by the chapter, as is shown in Fig. 15, we can see that the system identified the place name exited in the gazetteer accurately. We also manually identified the place name which is not listed in the gazetteer through generic names. Then, based on Lookup label set, combined with space place name for Inner Mongolia administrative units' ontology, we connected place name text fragments with ontology instances and completed information of each place name and finished the annotation of the document. In the end, we got structured document.

被调出的重点县包括经济发展较快和资源较为丰富的县区, 如陕西省榆林市下属的府 谷县、噇边县, 陕西省延安市下属的子长县、安塞县、吴起县、内蒙古鄂尔多斯市下属的准 格尔旗、鄂托克前旗、杭锦旗、乌审旗、伊金霍洛旗等。据了解, 本论名单调整由各省(区、 市)根据自身实际情况内部凯调, 各省(区、市)调入和调出县区数墨相同, 总数保持不变。共 有 9 个省(区、市)对各单进行微调, 12 个省(区、市)各单不变。调整后的国家扶贫开发工作 重点县位于中部地区的有 217 个, 西部地区有 375 个, 其中属于集中连片特殊困难地区范围 内的国家扶贫开发工作重点县有 440 个。

内蒙古自治区调出托克托县、和林格尔县、清水河县、固阳县、达尔帘茂明安联合旗、 克什克腾旗、准格尔旗、鄂托克前旗、杭锦旗、乌审旗、伊金霍洛旗、多伦县, 调入阿畐科 尔旗、科尔施左翼中旗、科尔施左翼后旗、莫力达瓦达斡尔族自治旗、鄂伦春自治旗、卓 资县、兴和县、阿尔山市、科尔他右翼前旗、突泉县、苏尼特右旗、正镶白旗。

Fig. 15. The reference documentation.

\section{Conclusion}

In this paper, based on identification and semantic annotation for temporal place name ontology for Inner Mongolian administrative units, we achieve the structured place name in the Mongolian documents, which provides convenience for semantic search for geographical information and the further construction of Mongolian Semantic Web

\section{Acknowledgments}

This work is partially supported by National Natural Science Foundation of China (61363052), Natural Sc ience Foundation of Inner Mongolia Autonomous Region (2012MS0904), College and University Scientific R esearch Project of Inner Mongolia Autonomous Region (NJZZ12046, NJZY14064) and Inner Mongolia Scienc e and Technology Plan Project (20130362).

\section{References}


[1] Dong, Z. J., Wu, J., \& Zhong, Y. X. (2004). Implementation of minority languages processing in ICU. Journal of Chinese Information Processing, 18, 66-72.

[2] Hua, S. B. (2004). The study of mongolia corpus construction. Journal of Conference of Institute of Ethnology and Anthropology, Chinese Academy of Social Sciences, 4,134-137.

[3] Liu, Y., Zhang, Y., Tian, Y. (2007). On general place names and the associated Ontology. Geography and Geo-Information Science, 23(6), 1-7.

[4] Du, P. (2011). Study on the ontology-based extractiong of the names chinese adminstrative division. LanZhou University, 2011.

[5] Grenon, P, \& Smith, B. (2004). Snap and span: Towards dynamic spatial ontology. Spatial Cognition and Computation, 4, 69-103.

[6] $\mathrm{Hu}, \mathrm{Y}$. (2008). Research on temporal relationship of ancient and modern place names in genealogy GIS. Nanjing Normal University.

[7] Gate Home. Retrieved December 05, 2008, from http://gate.ac.uk/.

[8] Wang Ya-bin. Research on Ontology-based Semantic Annotation[D]. Lanzhou University of Technology, 2010. (in Chinese)

[9] Nashun Wuritu, Chen Yu-zhong. The Research on Mongolian Language Standardization for Information Processing[J]. Inner Mongolia University. Chinese Information Processing Society of China. Hohhot. Inner Mongolia University, 2004,12-14. (in Chinese)

[10] M. Erdmann, A. Maedche, H.-p. Schnurr, S.Staab. From Manual to Semi-automatic Semantic Annotation: About Ontology-based Text Annotation Tools [J]. 2000:33-35.

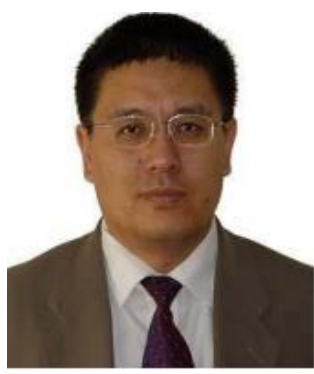

Yila Su was born in 1964 in Xilinhot City, Inner Mongolia, He is a professor. His current research interests include artificial intelligence, machine learning, data mining, computer networks and other aspects.

He is one of the early main member of researching areas of network intelligence, and published many articles.

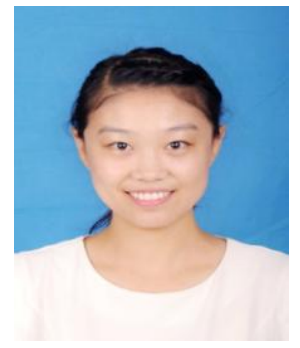

Huimin Li was born in Hohot City, Inner Mongolia, and she is a master whose major research areas include web intelligence, semantic web, etc. She is one of the studying student for master degree of professor $\mathrm{Su}$.

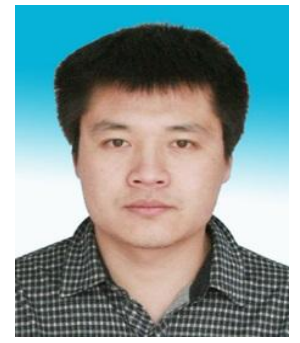

Fei Wang has received his master degree. He was born in Hohot City, Inner Mongolia, and his major research areas include web intelligence, semantic web, etc. He is one of the studying student for master degree of professor $\mathrm{Su}$. 